\title{
Seismic behaviour of vernacular architecture
}

CHAPTER · SEPTEMBER 2015

DOI: 10.1201/b18856-32

READS

103

4 AUTHORS:

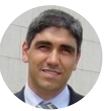

H. Varum

University of Porto

413 PUBLICATIONS 1,010 CITATIONS

SEE PROFILE

Paulo B. Lourenco

University of Minho

578 PUBLICATIONS $\quad 4,025$ CITATIONS

SEE PROFILE

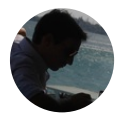

Hugo Rodrigues

Instituto Politécnico de Leiria

131 PUBLICATIONS 374 CITATIONS

SEE PROFILE

Graça Vasconcelos

University of Minho

104 PUBLICATIONS 349 CITATIONS

SEE PROFILE 


\title{
Seismic behaviour of vernacular architecture
}

\author{
H. Varum \\ CONSTRUCT-LESE, Department of Civil Engineering, Faculty of Engineering, University of Porto, Portugal
}

H. Rodrigues

RISCO - School of Technology and Management, Polytechnic Institute of Leiria, Portugal

P.B. Lourenço \& G. Vasconcelos

ISISE, Department of Civil Engineering, University of Minho, Guimarães, Portugal

\section{INTRODUCTION}

Vernacular constructions are widely present in the built environment of many regions. Being nonengineered constructions, they result from the use of traditional materials and techniques, continuously improved based on the observations of their performance and response to different requirements and demands imposed by the social and physical environment.

It is commonly accepted that vernacular architecture have been continuously adapting to the local climate, extreme loadings, type of use, to the environment in which is inserted, etc.. Thus, during centuries man has developed some constructive techniques to reach the comfort and performance desired, function of the local climatic conditions, the available materials and other conditions relating to their culture (Cañas \& Martín, 2004).

In earthquakes, vernacular construction may suffer considerable damage, and eventually collapse, with the consequent economic losses, injuries and deaths. Some vernacular buildings are particularly vulnerable to earthquakes, in most cases due to the overall layout of the construction, to the connection between structural elements, poor constructive details and poor maintenance. Recent earthquake events have shown the vulnerability and limited capacity of some vernacular solutions, which may induce a poor seismic performance.

\section{VERNACULAR CONSTRUCTION}

\subsection{Concepts}

It has been estimated that $90 \%$ of the construction around the world is vernacular type, meaning that it is for daily use (University).

A vernacular construction reflects the period of time, the local environmental, the cultural, technological and historical context of the society, representing a cost-effective construction based on the local available materials.

The vernacular constructions were usually constructed to meet the needs of the residents, considering the local climate, available materials, and natural hazards that may suffer.

\subsection{Local available materials}

The structural behaviour of a vernacular construction is clearly influenced by the building technology, construction details and the used materials.

Earth, stone or brick masonry elements and timber are the most frequently used structural materials, and their combination was currently adopted in vernacular constructions.

Earth construction solutions are among the most important materials/techniques used in vernacular construction. In fact, it is estimated that, even nowadays nearly $50 \%$ of the world's population lives in earthbased constructions (Guillaud, 2008). Besides the evidences in less developed countries where this type of construction is very popular, it can be largely found in some developed regions, due to the sustainable construction concerns and practices. The number of earth-based buildings tends to increase 
(Pacheco-Torgal \& Jalali, 2012). Earth has been used in vernacular constructions, with several different techniques, such as rammed earth, adobe, Daub and wattle, cob, among others.

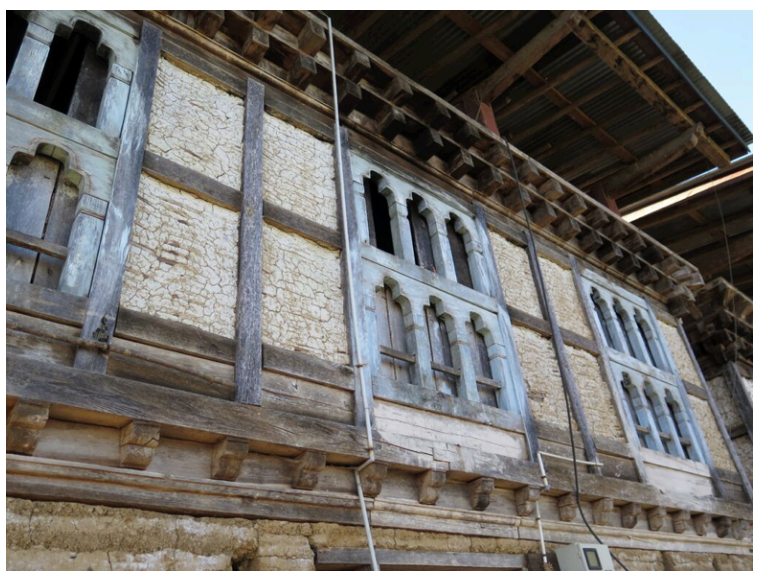

Figure 1 - Timber construction in Bhutan ONCREP 2015

The success of a certain type vernacular constructions may be related with the available raw materials, like is the case of adobe construction in Aveiro district, Portugal. The principal raw materials used in the production of the adobes in the region were coarse sand, argillaceous earth and lime. Worldwide, in the vernacular architecture, for the production of adobes, to natural earth can be added clay or sand, and it was also common the addition of natural fibers (as straw or sisal, for example) to control cracking during adobes drying in the sun (Silveira et al., 2012).

But the use of raw earth was associated to other construction techniques, adapted to the local construction practices, materials and needs. For example, in Portugal, "tabique" elements were used in different constructions in all the country. In fact, it is one of the most used traditional building techniques using raw materials, particularly for interior partition walls. A tabique constructive element can be simply described as a timber structure, more or less complex and robust, filled and plastered in both sides by a composite earth based material (Silveira et al., 2012).

\subsection{Seismic resistant constructive elements}

One of the important characteristics of the built vernacular heritage is related with its adaptation to the environment constraints, and in many situations it is evident the relation with the natural hazards incidence (Ortega, Vasconcelos, \& Correia, 2014).

The occurrence of a strong natural extreme event, or the repetition of small events, like earthquakes, may push the community to react and to transpose this to act in the construction practices, developing a local risk culture (Ferrigni et al., 2005). These actions may include the production of earthquake safer features added in the current construction practice following a seismic event, which has caused damage. Methods and solutions that revealed to be vulnerable are either abandoned or modified/improved and in reconstruction works the details and solutions which have withstood the event are adopted again. Eventually, these aseismic features can take root in the building culture of the region (Jigyasu, 2002).

D'Ayala (D. D'Ayala, 2004) observed that in regions of moderate seismicity, corner returns and quoins, connection with partition walls, regular masonry fabric (stone or brickwork), floor and wall ties, alternate orientation of floor structures can typically be found, while in regions of higher seismicity, these features are accompanied by timber ringbeams, monolithic lintels and stone frames around openings, framing and bracing of masonry with timber post and struts.

For example, the use of timber elements within walls found in Pombalino buildings, in Portugal, and in traditional constructions in Greece, Turkey and India has been used to improve the earthquake performance of these buildings (Pacheco-Torgal \& Jalali, 2012).

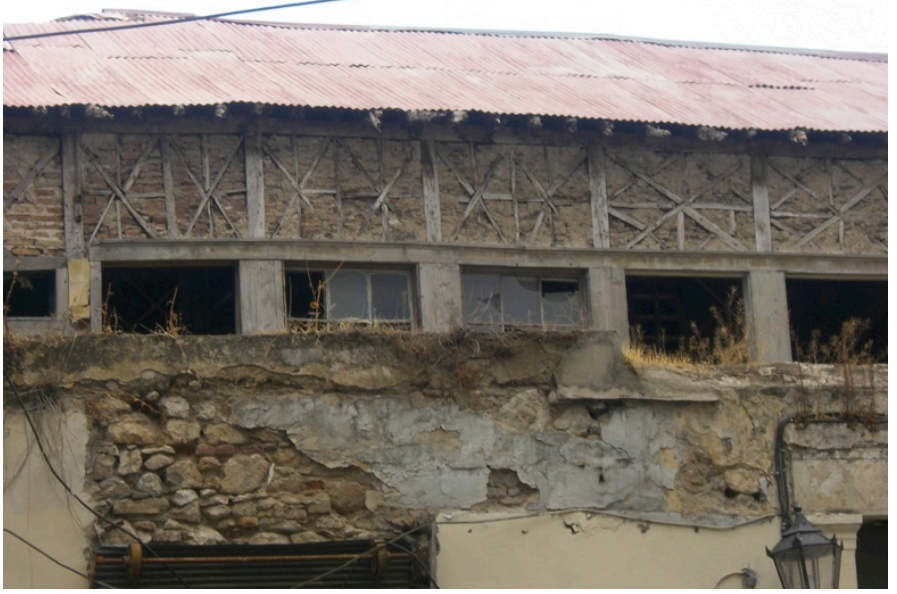

Figure 2 - Timber elements within walls in Greece

In seismic prone regions is common to find elements for the improvement of the connection between structural elements (ties and reinforcing rings); and construction elements that counteract the horizontal forces in earthquakes (buttresses and reinforcement arches).

Metal and wooden ties have been applied for a long time as a reinforcement measure in highly seismic regions, such as Italy (Figure 3 ). This type of strengthening measure has been also adopted in Portugal in order to improve the structural stability. 


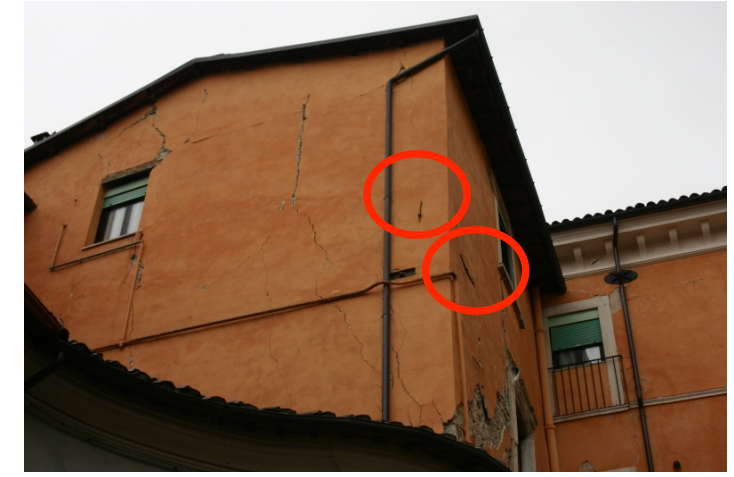

Figure 3 - Ties in a traditional masonry building, L'Áquila, Italy

Buttresses can be found in ancient constructions, built at the same time as the building, as a deliberated feature, or they can be added to older masonry, as a consolidation, reinforcement or stability improvement measure. Buttresses can counter the rotation of the façade thanks to their sheer mass. They can be found again, in many of the highly seismic regions, where masonry is the main construction system. Buttresses are also common in vernacular architecture, being introduced to counteract the lateral forces imposed by roof systems, arches and vaults (Ortega et al., 2014). They may also have a seismic concern origin and they can still be found in many vernacular buildings.

In urban environments, other elements that may play a similar reinforcement role are external stairs, counter arches between buildings, vaulted passages and loggias.

\section{VERNACULAR BUILDINGS AND EARTHQUAKES}

Past and recent destructive earthquakes proved that most of severe damage and collapses may occur on non-engineered buildings. As stated before, vernacular constructions result from traditions, improved with time as a response to the requirements of their social and physical environment. As so, in seismic regions, where small or moderate earthquakes are frequent, these events influence the construction practice and, thus, influences the requirements for the structural capacity of these buildings. Consequently, several elements are incorporated in the traditional construction for their seismic behavior improvement.

However, in many situations, the poor economic condition of habitants, the state of conservation of the buildings, and the large recurrence period of this type of extreme events leads to neglecting the importance of these elements.

Even with good construction practices, and incorporating seismic improvement construction practices, for strong earthquakes it may be difficult to assure an adequate behavior for certain type of construction, as for the ones with high mass, like loadbearing masonry structures.

In L'Áquila 2009 earthquake, several vernacular buildings have showed a deficient behavior under the seismic demands they suffered. The substantial re-adaptation and changes of their structural system in the last 50 years, to account for a different use of the spaces, the consideration of modern residential requirements for comfort, may have influenced their seismic performance, contributing to several damage mechanisms identified (DinaF D'Ayala \& Paganoni, 2011). The original structures include both, masonry vaults and timber floors and roofs, replaced in recently retrofitted buildings by lightweight jack arches or steel beams (DinaF D'Ayala \& Paganoni, 2011).

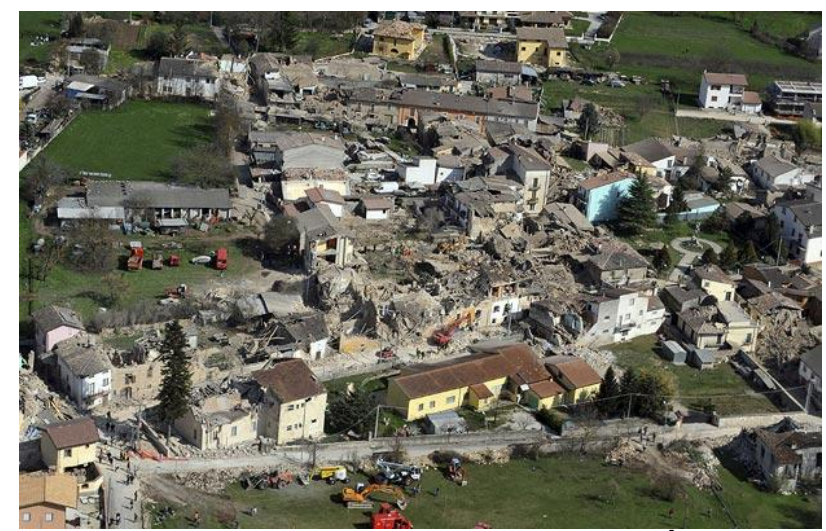

Figure 4 - Village affected by the L'Áquila earthquake

In L'Áquila, several collapses of the building façades due to poor connections between walls were found and the quality of masonry dramatically influenced the level of damage (see figure 5).

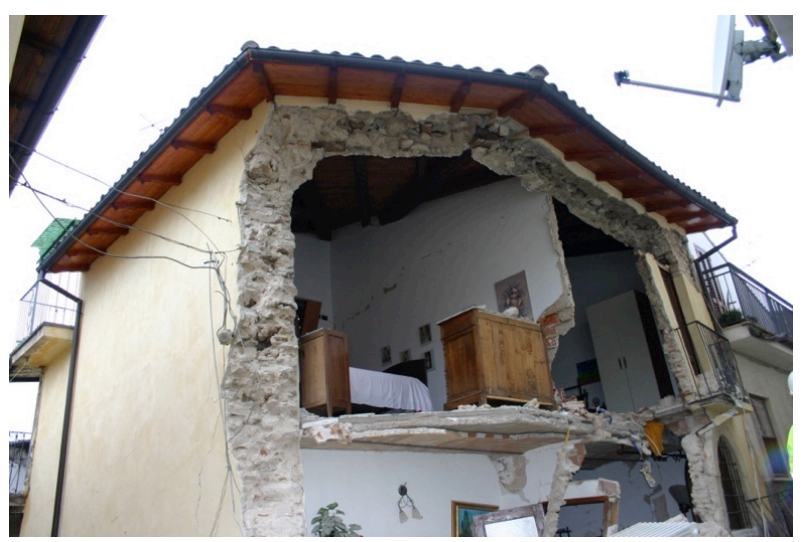

Figure 5 - Out-of-plane collapse of a façade masonry wall

The seismic performance of traditional masonry constructions retrofitted with ties may be influenced by their location, by the material deterioration of the 
anchor element, or by the lack of integrity and shear capacity of the masonry to withstand the thrust generated at the anchoring plate/element by the relative movement of the two orthogonal walls (Rodrigues et al., 2010).

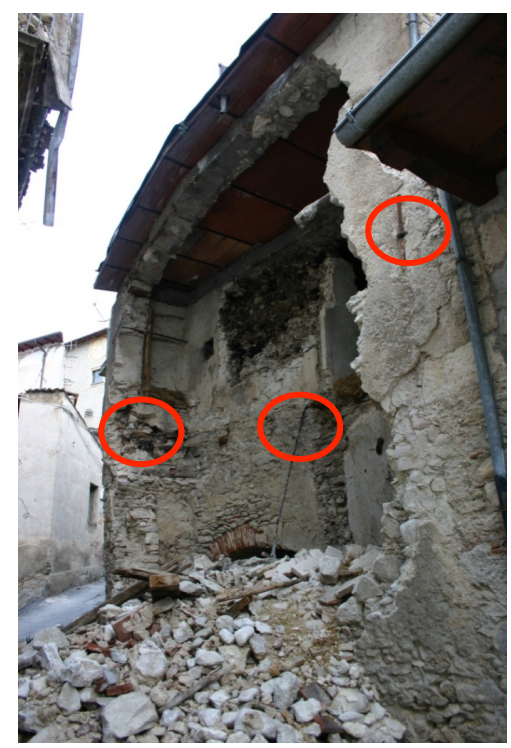

Figure 6 - Collapsed façade of a building with ties, during L'Áquila earthquake

Vernacular buildings are a relevant part of the building stock affected by the Emilia, 2012, earthquakes (Paupério et al., 2012), mainly due to the overall layout, constructive details and poor maintenance. Many of the building in the affected area have shown a very poor seismic performance. Approximately two hundred rural buildings suffering from partial to total collapse have been counted in an area of about $500 \mathrm{~km}^{2}$ (Sorrentino, Liberatore, Liberatore, \& Masiani, 2014).

The main cause of damage in these buildings is associated with the higher length/thickness and height/thickness ratios of the walls and with the use of slender brick columns, connected to the roof just by friction (Sorrentino et al., 2014).

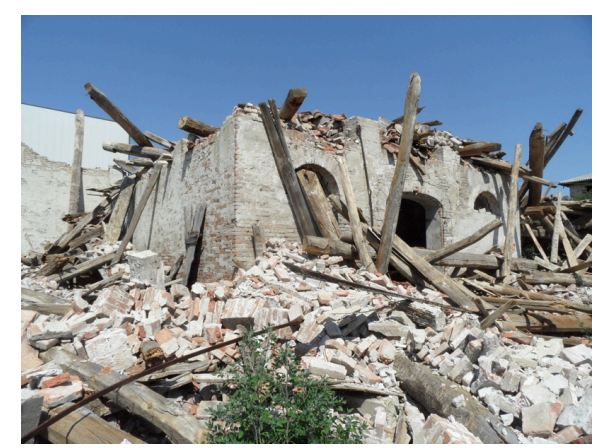

Figure 7 - Masonry buildings collapsed during the Emilia-Romagna earthquake

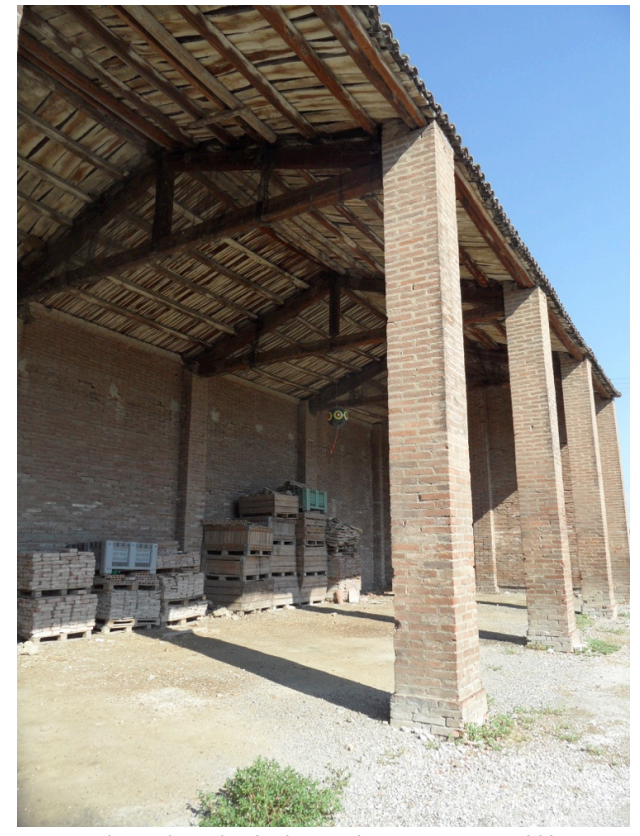

Figure 8 - Slender brick columns Emilia-Romagna region

The 7.8 magnitude earthquake that hit Nepal on the $25^{\text {th }}$ of April 2015, and the series of aftershocks that followed it, associated with a high number of human losses, severely affected numerous vernacular buildings. In remote areas like, Gorkha, Dolakha, Sindhupalchowk, Nuwakot, Solukhumbu, Kavre, Rasuwa and Dhading, the majority of houses were vernacular constructions. Locally available stone with mud mortar or, in many cases, without binding material are common construction solutions in those areas.

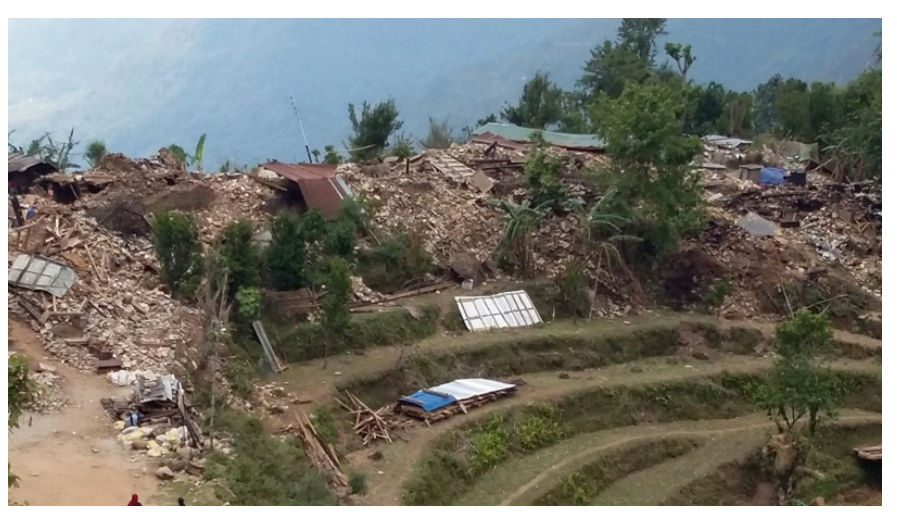

Figure 9 - Collapsed houses of an entire community near Barpak during the Gorkha earthquake, 2015 CDipendraGautam 2015

In the worst affected area, traditional single-storey masonry houses without, or with poor, binding material were the most common building typology. In Barpak of Gorkha (the worst affected area, beside the epicenter region) the majority of adobe houses collapsed. The out-of-plane failure mechanism was commonly observed in many houses. 


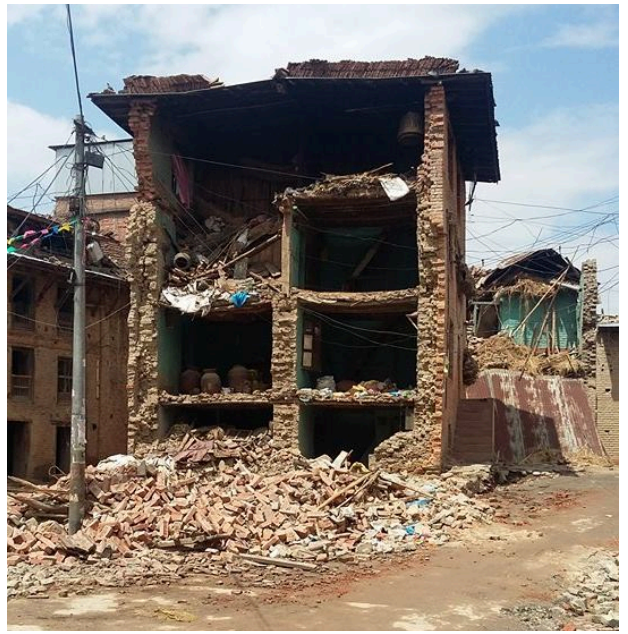

Figure 10 - Out-of-plane façade failure during the Gorkha earthquake, 2015 ODipendraGautam 2015

In many houses, the roofing system was found to be heavier than in other typologies. Many of those observed houses had roofing systems with stone covering (Fig. X). Due to climatic condition, people were adopting the use of heavy stone roofs and avoiding timber elements and other lighter solutions in adobe masonry houses, so probably damage was further intensified by this constructive option.

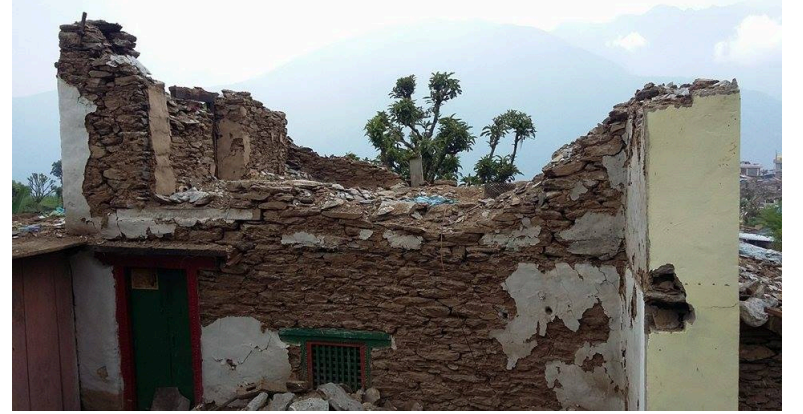

Figure 11 - Collapsed house with a heavy roof during the Gorkha earthquake, 2015 ODipendraGautam 2015

\section{ELEMENTS AFFECTING SEISMIC BEHAVIOUR}

From the previous section is clear the influence of the material properties and constructive solutions and details are critical for the structural behavior of vernacular buildings. Based on the observations from damages and collapses in previous earthquakes some parameters were identified that can influence significantly the structural behavior of these buildings (Ortega et al., 2014).

One of them is the interaction between buildings, which has a significant influence in the seismic performance of structures. The interaction between adjacent buildings with different dynamic behavior may have implications on the seismic behavior and performance of the structures.

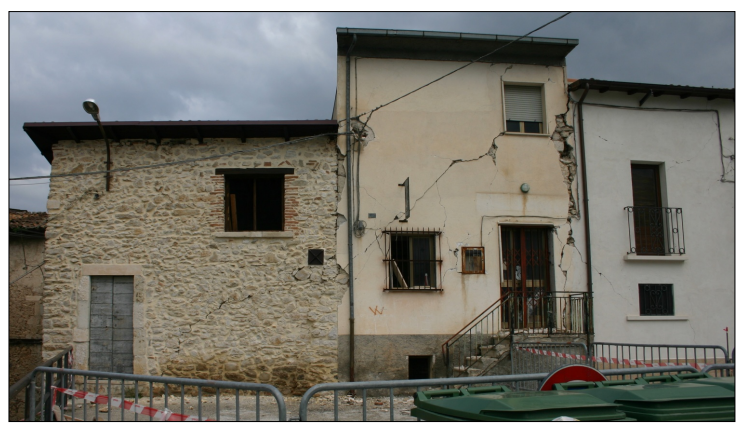

Figure 12 - Damage associated to the interaction between adjacent buildings - L'Áquila earthquake

The shape of the building plays an important role if the regularity in plan and in elevation. Lacking of shape regularity in plan may induce an irregular distribution of the seismic demands, due to the eccentricity between the center of mass relatively to the stiffness center, enforcing the torsional demands due earthquake actions. Regarding the typologies of walls, they can differ in the constituent material, in the quality of the material, in the arrangement of the elements/units, having a significant influence in the capacity of the masonry and so of the building to support vertical forces and to withstand the horizontal demands resulting from seismic actions.

The diaphragms at the floor level may be very flexible, when wooden floors are used, which is the most common solution. Proper connections between walls and floors are important, so that the vertical structural elements do not behave independently and improving the coupled response of the building. Excessive deformability of the floors may have a negative effect on the behavior of the façade walls. To assure the proper "box-behavior", assuring that all structural elements contribute to the structural resistance of the building, the connections between structural elements should be carefully considered. In many cases, the walls work separately, having to bear by themselves portion of load that acts on them (Ortega et al., 2014).

Strengthening devices, like ties, buttresses and other reinforcement elements can improve the structural behavior of the buildings and, in particular, enhance the connection between structural elements (ties and reinforcing rings). Other construction elements can counteract part of the horizontal demands due to earthquakes, as buttresses and reinforcement arches.

Another important aspect that influences significantly the seismic behavior of vernacular buildings is associated with the alterations and/or inadequate interventions. Addition of floors and new elements or spaces, and removal of existing strengthening elements may changes significantly the structural behavior of the original building. 


\section{FINAL REMARKS}

Vernacular construction is, in many cases, the primary construction system in certain rural areas, but that is the situation also in many urban areas, where an important heritage is present.

In vernacular construction, the materials and construction techniques are very different around the world and in many cases elements to improve the seismic behavior of the building are included.

Seismic deficiencies of vernacular constructions are, in many cases, associated to the heavy weight of the structures, their low strength, brittle behaviour, and deficiencies in the connections between structural elements. The primary factors affecting the structural performance of a vernacular construction, in particular for earthquake actions, is the position of the building and its relation with adjacent buildings, the presence of irregularities, the construction solutions and the quality of the materials, the lack of maintenance, eventual alterations and damage due to previous extreme events. Also, the adequate connection between the walls and floor/roof system is essential to prevent collapse.

\section{ACKNOWLEDGEMENTS}

The authors gratefully acknowledge the partial support by the research project 'SEISMIC-V - Vernacular Seismic Culture in Portugal' (PTDC/ATP-AQI/ 3934/2012), from the Portuguese Science and Technology Foundation (FCT).

\section{REFERENCES}

Cañas, I., \& Martín, S. (2004). Recovery of Spanish vernacular construction as a model of bioclimatic architecture. Building and Environment, 39(12), 1477-1495. Doi: http://dx.doi.org/10.1016/j.buildenv.2004.04.00 7

D'Ayala, D. (2004). Correlation of fragility curves for vernacular building types: houses in lalitpur, nepal and in istanbul, Turkey. Paper presented at the 13th World Conference on Earthquake Engineering Vancouver, B.C., Canada

D’Ayala, D., \& Paganoni, S. (2011). Assessment and analysis of damage in L'Aquila historic city centre after 6th April 2009. Bulletin of Earthquake Engineering, 9(1), 81-104. Doi: 10.1007/s10518-010-9224-4

Ferrigni, F., Helly, B., Mauro, A., Victor, L. M., Pierotti, P., Rideaud, A., \& Costa, P. T. (2005).
Ancient Buildings and Earthquakes. The Local Seismic Culture approach: principles, methods, potentialities.

Guillaud, H. (2008). Characterization of earthen materials. In H. G. E. Avrami, M. Hardy (Ed.), Terra literature review - an overview of research in earthen architecture conservation (pp. 21-31). Los Angeles (United States) The Getty Conservation Institute.

Jigyasu, R. (2002). Reducing Disaster Vulnerability through Local Knowledge and Capacity. The case of Earthquake Prone Rural Communities in India and Nepal. (phd Thesis), Norwegian University of Science and Technology, Trodheim.

Ortega, J., Vasconcelos, G., \& Correia, M. (2014). An overview of seismic strengthening techniques traditionally applied in vernacular architecture. Paper presented at the 9th International Masonry Conference, Guimarães.

Pacheco-Torgal, F., \& Jalali, S. (2012). Earth construction: Lessons from the past for future eco-efficient construction. Construction and Building Materials, 29(0), 512-519. Doi: http://dx.doi.org/10.1016/j.conbuildmat.2011.10 .054

Paupério, E., Romão, X., Tavares, A., Vicente, R., Guedes, J., Rodrigues, H., . . Costa, A. (2012). Survey of curches damaged by the May 2012 Emilia-Romagna eartquake sequence (pp. 27): Faculty of Engineering of the University of Porto and University of Aveiro.

Rodrigues, H., Romão, X., Costa, A. G., Arêde, A., Varum, H., Guedes, J., Paupério, E. (2010). Sismo de L'Aquila de 6 de Abril de 2009. Ensinamentos para Portugal". Paper presented at the $8^{\circ}$ Congresso Nacional de Sismologia e Engenharia Sísmica - SISMICA 2010, Aveiro, Portugal.

Silveira, D., Varum, H., Costa, A., Martins, T., Pereira, H., \& Almeida, J. (2012). Mechanical properties of adobe bricks in ancient constructions. Construction and Building Materials, 28(1), 36-44. Doi: http://dx.doi.org/10.1016/j.conbuildmat.2011.08 .046

Sorrentino, L., Liberatore, L., Liberatore, D., \& Masiani, R. (2014). The behaviour of vernacular buildings in the 2012 Emilia earthquakes. Bulletin of Earthquake Engineering, 12(5), 2367-2382. Doi: 10.1007/s10518-013-9455-2

University, O. O. B. Centre for Vernacular Architecture Studies, International Studies in Vernacular Architecture, brochure 